\title{
Reform of Four-in-One Practical Education System to Promote the Personnel Training in Chinese Pharmaceutical Engineering Major
}

\author{
Xiaoyan Luo, Gonghua Song, Weiping Deng, Fuzheng Ren, Hongwei Liu \\ School of Pharmacy, East China University of Science and Technology, Shanghai, China \\ Email:xyluo@ecust.edu.cn
}

How to cite this paper: Luo, X. Y., Song, G. H., Deng, W. P., Ren, F. Z., \& Liu, H. W. (2018). Reform of Four-in-One Practical Education System to Promote the Personnel Training in Chinese Pharmaceutical Engineering Major. Creative Education, 9, 625-632.

https://doi.org/10.4236/ce.2018.94044

Received: February 26, 2018

Accepted: April 15, 2018

Published: April 18, 2018

Copyright $\odot 2018$ by authors and Scientific Research Publishing Inc. This work is licensed under the Creative Commons Attribution International License (CC BY 4.0).

http://creativecommons.org/licenses/by/4.0/

(c) (i) Open Access

\begin{abstract}
In order to cultivate students' engineering capabilities and quality management capabilities, the "four-in-one" three-dimensional practice teaching system was reformed, which includes professional experiment on campus, holographic electronic sand table and simulation training on campus, off-campus enterprise practice and off-campus design competition. All of them are considered as a continuous, interactive whole. Firstly, experimental contents were condensed to form a small test synthesis of raw materials, process optimization, pilot-scale integrated design experiments and a professional engineering experimental teaching system so as to enhance students' understanding and practice of drug engineering process. Secondly, modern pharmaceutical companies' holographic projection electronic sand table and simulation training system was created. At the same time, the new teaching model of "sand table learning-simulation training-enterprise internship" was put forward and adopted. Finally, we not only built the practice base of internationally renowned pharmaceutical enterprises, but also expanded practical teaching contents so as to cultivate student engineering accomplishment and drug quality management capabilities.
\end{abstract}

\section{Keywords}

Practical Education System, Holographic Electronic Sand Table, Professional Experiment, Off-Campus Enterprise Practice, Design Competition

\section{Introduction}

Since the Chinese pharmaceutical engineering major for the undergraduate education was first set up in 1998, there have been more than 300 universities 
setting this major, which becomes the professional support of the Chinese pharmaceutical industry (Xu et al., 2004). The core elements of pharmaceutical engineering professionals are the students' engineering ability and accomplishment. It is engineering practice teaching that cultivates the students efficiently to have these elements, thus it has always been the forefront of the education reform in pharmaceutical engineering major.

As the putting forward and developing of pharmaceutical new concept, new technology and series of laws and regulations, we have explored and innovated on the pharmaceutical engineering practical education system in recent years, taking "How To Foster Students Engineering ability and Innovative" as purpose and insisting on the concept of "students-centered, process-conscious and innovation-inherited".

We have reformed the "four-in-one" three-dimensional practical education system. This system includes in-campus specialized experiment, in-campus electronic sand table and simulation training, off-campus internship and design competition that are considered as the continuous, interactive, complete whole (as shown in Figure 1). This system is helpful to cultivate students' engineering thinking and ability, professional accomplishment, management awareness and ability of drug quality in all directions, angles and depths; therefore, it is necessary to detail the system and its application herein.

\section{Reform}

\subsection{Construction the Specialized Experiment System of Pharmaceutical Engineering}

There are many reports on the teaching contents of specialized experiments (Yan et al., 2008; Chang et al., 2015; Chen \& Miao, 2016; Tang et al., 2014; Fang \& Li, 2016; Zhang et al., 2013; Wu et al., 2016; Huang \& Hu, 2016; Ye, 2012;

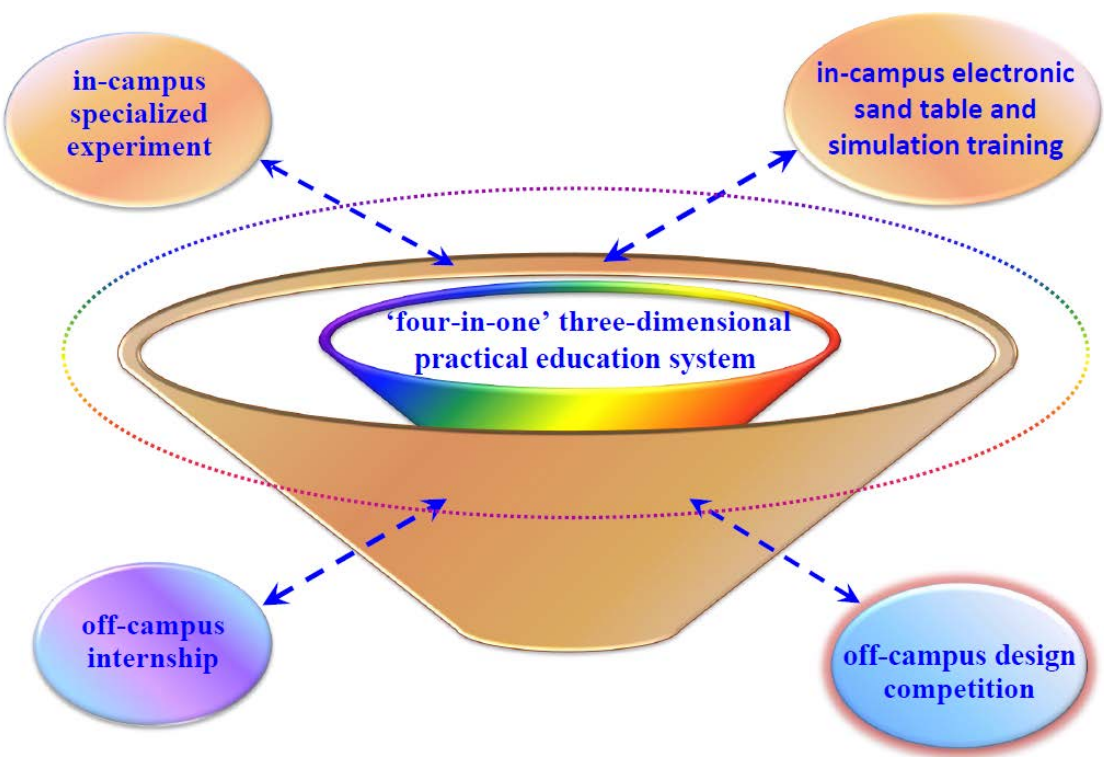

Figure 1. "Four-in-one" three-dimensional practical education system. 
Wang et al., 2016). However, the existing specialized experimental teaching system consists of a simple superposition of experimental contents independently designed according to the teaching contents of the various courses, so that there is a lack of interlink and correlations among these various contents. Therefore, it is difficult to strengthen the students' understanding and practice in the process of drug engineering research and development through specialized experiments. In order to solve this problem, the original Comprehensive Experiment of Pharmaceutical Engineering course was split into three specialized experiment courses-Experiment of Drug Synthesis, Experiment of Pharmaceutical Process and Special Experiment of Pharmaceutical Engineering-from 2013 undergraduate major, so as to be carried out in stages at different levels.

Moreover, we modularized core knowledge and condensed experiment contents to form a comprehensive design experiment covering the small-scale synthesis, process optimization and pilot scale production of raw material medicine, relying on our teachers' scientific research advantages. For example, simulating process procedure of fine-dry-package, drafting out crystallization engineering experiment, and three-in-one engineering experiment of centrifugation, washing and drying, which entail students to grasp the characteristics, equipments and principles of crystallization, filtration, drying, packaging and other unit operations.

\subsection{Creation of a Modern Pharmaceutical Enterprise Holographic Projection Electronic Sand Table and Simulation Training System}

We has created a modern pharmaceutical enterprise holographic projection electronic sand table and simulation training system (as shown in Figure 2) to form a teaching platform with combination of theory and reality, virtuality and reality. This system mainly composes the physical sand table model, holographic projection, three-dimensional video, three-dimensional virtual simulation training.

Moreover, it fully shows the real production scene of modern pharmaceutical companies by using the real production environment of pharmaceutical company's preparation and chemical raw materials as the background, through the sound, light, electricity, images, $3 \mathrm{D}$ animation and the integration of computer
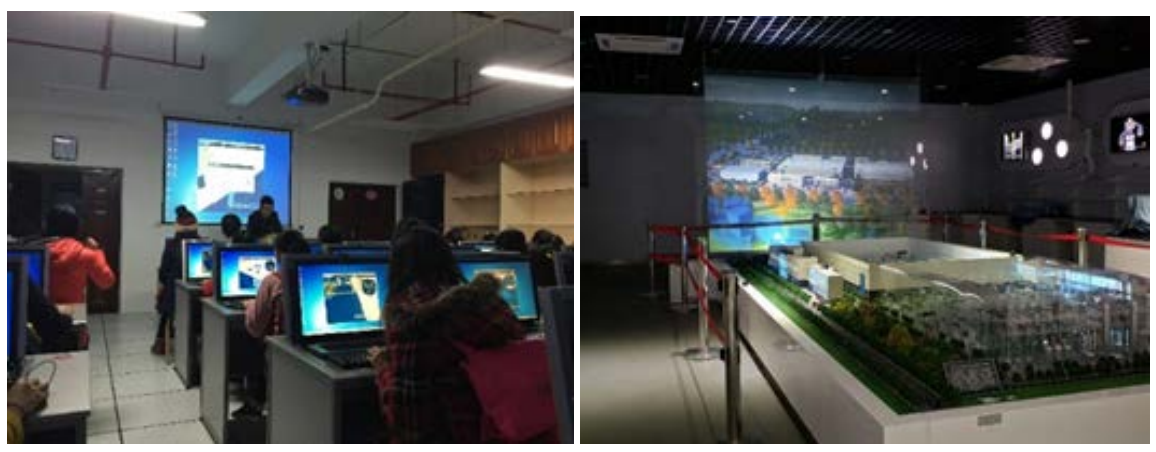

Figure 2. The modern pharmaceutical enterprise holographic projection electronic sand table and simulation training system. 
programmed technology and solid models. Training software and explain video were designed to match the sand table. This system also take the typical pharmaceutical production process as the main line, allowing students to simultaneously learn all production processes involved in the "human, machine, material, rule, environment" six major elements of drug production. Through this system, learners can experience a process of theory-practice-theory. Thus, this system have solved the pharmaceutical engineering training difficulties, such as students' safety, equipment operation, GMP management, shortage of money and field (Liu et al., 2012; Ye \& Li, 2014; Luo \& Xie, 2017).

\subsection{Development of a New Model of Internship Teaching and Content and Business Practice Bases}

Due to the particularity of drug production, it is difficult for students to internship in the clean production areas, which will restrict the cultivation of qualified personnel. Therefore, a new internship teaching mode, "sand table learning-simulation training-enterprise internship", is put forward and adopted (as shown in Figure 3). This teaching mode and its contents have the combination of "real imaginary" and achieved the purpose of internship with multiple levels and complementary contents. The teaching model, "Sand table learning-simulation training", can solve the problem that students have difficulty internship in the clean production areas, enabling students to fully understand and master the knowledge of technology, equipment, plant facilities and GMP knowledge. Corporate internships enable students to experience real corporate environment, culture, safety, quality management systems and production operations.

We increased the number of internationally renowned pharmaceutical companies practice bases. Apart from the practice of process, equipment and other

\section{Practical level}

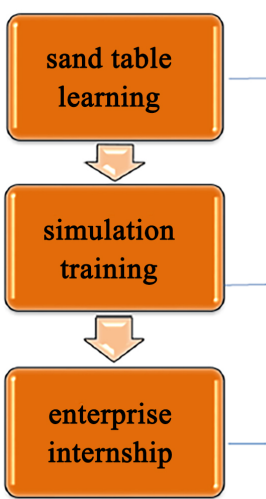

Figure 3. The teaching contents of various practical level.

\section{Content}

\section{general layout of factory, plant facilities, plant layout} structural feature and function of equipment, process

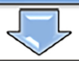

simulate the production staff for production, including equipment operation, material transfer, document filling, quality management, access to clean areas

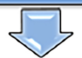

corporate culture, safety, waste treatment, pharmaceutical water system, air conditioning and purification facilities, warehouse management,deviation surveys, quality analysis, quality assurance, verification, visiting the production situation standing in the visiting corridor 
hardware facilities which are always paid attention by teachers (Zhang et al., 2015), the international advanced pharmaceutical enterprises 'concept and system of quality assurance of pharmaceutical production, the ethics of pharmaceutical engineering, team spirit and corporate culture are integrated into our practice teaching process so as to strengthen students' professionalism and quality awareness. For example, in the past three years, our students went to practice or do graduation theses in Boehringer Ingelheim (BI Company), a major multinational pharmaceutical company. Apart from enhancing their knowledge and skills, they have been promoted in professional ethics, enterprise standardization management, and drug quality management. Table 1 is an example of an internship position outside the production operation workshop.

Since September 2013, 23 new off-campus enterprise practice bases have been added, which effectively guarantee students to have more chances to practice and do their graduation thesis or design outside the universities, including Shanghai Syntheall Pharmaceutical Co., Ltd., Shanghai XinyiBailu Pharmaceutical Co., Ltd, Shanghai Tasly, Shanghai Tengrui Pharmaceutical Co., Ltd, Suzhou Tianma Pharmaceutical Group Co., Ltd., Shanghai Pukang Pharmaceutical Co., Ltd., Shanghai Hualian Pharmaceutical Co., Ltd., Shanghai Fenglin Biotechnology Co., Ltd..

\subsection{Improvement of the Engineering Design Teaching System}

Each year, we organize and guide our students to participate in the National Pharmaceutical Engineering Design Contest, which helps to guide and motivate students to understand the development trend and technical requirements of the modern pharmaceutical industry, to learn new concepts of engineering design, to use advanced design tools and software, and to strengthen students'

Table 1. Examples of the remaining internship positions in BI company.

\begin{tabular}{|c|c|}
\hline Internship position & Content \\
\hline Quality assurance & Deviation investigation, product release \\
\hline Quality control & $\begin{array}{l}\text { Manual operation and QC package test are required in the chemistry } \\
\text { lab }\end{array}$ \\
\hline Quality verification & $\begin{array}{l}\text { Production equipment and laboratory equipment qualification, } \\
\text { verification of transportation, excel spreadsheet validation, validation } \\
\text { of computerized systems, utility qualification }\end{array}$ \\
\hline Quality system & $\begin{array}{l}\text { Document management, GMP training system, supplier } \\
\text { management, change control }\end{array}$ \\
\hline & $\begin{array}{l}\text { Sanitary control of clean areas, production process and key quality } \\
\text { control of a product, skills matrix of production position, repeatedly } \\
\text { found items during route inspection and self-inspection internal }\end{array}$ \\
\hline Production management & $\begin{array}{l}\text { audit, balanced scorecard, production plan arrangement, key process } \\
\text { control points and basic concept of SPC, basic concept of lean } \\
\text { production, visual management and } 5 \mathrm{~S} \text { management concept, solid } \\
\text { lean packaging project }\end{array}$ \\
\hline
\end{tabular}


professional ability of comprehensive utilization, engineering design ability and team spirit.

We take the new design guidance model-"sand table and simulation traininginternship in the relevant pharmaceutical companies-design" to guide students. We also introduce the contest content into the design teaching work, and impart new technologies and tools learned in the competition to our students so as to realize the overall guidance and benefit of the all students.

Furthermore, we purchased CADWorx, a three-dimensional design software that is widely used in the pharmaceutical industry. Through three-dimensional design, we not only make students 'works more demonstrative, but also let students know the design processes and methods in design companies. Students have used this software in the design competition for the past three years and their works have shown good results.

A high quality, strong, ladder engineering design instructor team was produced. In recent years, the overwhelming majority of young teachers in colleges and universities have doctorates and strong research abilities. However, they lack practical experience in engineering and design capabilities, so it is difficult for them to guide students to carry out engineering practice, which will restrict the effective execution of Excellent Engineers' Plans. Young teachers went to the design institute to practice and participated in the training organized by the organizing committee of the competition. We also invited design institute experts to conduct a series of lectures on young teachers at our college so that they can systematically understand and master the design of pharmaceutical engineering.

\section{Application and Results}

\subsection{The Benefits of Electronic Sand Table and Simulation Training System for Education}

Simulation training system is accepted and used by many colleges and universities in China. Moreover, the sand table and simulation training system was first introduced on the annual meeting of pharmaceutical engineering in 2015 and got a good feedback. This system has been used in 15 colleges and universities and 12 training schools since 2015.

The electronic sand table and simulation training system are also used in GMP course, Industrial Pharmacy course, Pharmaceutical Engineering course, Pharmacy Training and many other professional courses. For example, we used the "teaching first-training second or teaching while training" teaching method in GMP course to improve students learning efficiently, arouse students interest in learning, uplift students' learning efficiency, and realize the teaching contextualization and teaching resources informatization.

Because the sand table and simulation training system has repeatability, automatic guidance and knowledge explaining functions, students can carry out autonomous learning through it, which have strengthen students' learning efficiency, and expanded student's field of vision. 


\subsection{The Benefits of Student Engineering Training Expanded and Fruitful Results}

Due to the enhancement of students' interest in engineering and the improvement of teachers' engineering design and guidance, the proportion of students who carried out graduation design has increased from about $20 \%$ to $40 \%$.

Many students actively participate in the National Pharmaceutical Engineering Design Contest with excellent results. During 2014-2017, 72 students took part in the competition and won 4 first prizes, 3 second prizes, 3 third prizes and 1 best wall poster award.

The increase of practice bases ensured the effective implementation of Excellent Pharmaceutical Engineers' Plan. In the first three sessions, i.e. 2014-2016, the number of students enrolled in our Excellent Pharmaceutical Engineer s' Plan was about 30 students respectively. In 2017, the number of students increased to about 50, and all of them went to the enterprises for one year's corporate practice-internship and graduation thesis or design.

\subsection{Strong Competitiveness of Graduates}

In recent three years, the proportion of graduates furthering study in colleges and universities have reached $45 \%$ to $51 \%$. Many graduates went to well-known universities abroad (such as Columbian University, Cornell University), Chinese Academy of Sciences and famous universities in China (such as, Tsinghua University and Shanghai Jiao Tong University).

Many graduates were deeply welcomed by the pharmaceutical enterprises and institutions for their strong abilities and cleverness. The employment fields of graduate were mainly concentrated in the pharmaceutical industries, including, the state-owned large and medium-sized enterprises, private enterprises, and world top500 enterprises or joint ventures, such as, Shanghai Food and Drug Administration, Shanghai Pharmaceuticals Group Co. Ltd., China National Pharmaceutical Group Corporation (Sinopharm), Pharmatechs Co. Ltd., Pfizer, Merck, Johnson and Glaxosmithkline, etc.

\section{Conclusion}

We have reformed "four-in-one" three-dimensional practice teaching system to cultivate students' engineering capabilities and quality management capabilities in all aspects, angles and depths. This system included professional experiment on campus, holographic electronic sand table and simulation training on campus, off-campus enterprise practice and off-campus design competition which were considered as a continuous, interactive whole. However, the sand table is limited to solid oral preparations and chemical raw material medicines, so it needs to be expanded in terms of the types of drugs, and specially combined with VR to make the effect better.

\section{References}

Chang, H.-H., Li, X., Zhang, R., Cao, Q., \& Wei, W.-L. (2015). Exploration and Practice 
of Integrated Experimental Teaching in Pharmaceutical Engineering Specialty. Education Teaching Forum, 18, 124-125.

Chen, X.-B., \& Miao, J.-N. (2016). Exploration and Practice of Pharmaceutical Engineering Course Experimental Teaching. Guangdong Chemical Industry, 3, 135-141.

Fang, S., \& Li, Q.-Q. (2016). Experimental Teaching of Drug Synthesis. Guangzhou Chemical Industry, 44, 208-209.

Huang, Q., \& Hu, G.-Q. (2016). Exploration of Systematic Experimental Teaching Practice in Pharmacy Engineering Major. Pharmaceutical Education, 32, 77-79.

Liu, F.-H., Zhang, Y., \& Zhao, H. (2012). Research on New Mode of Practice in Pharmaceutical Engineering. Pharmaceutical Education, 28, 47-49.

Luo, X.-Y., \& Xie, H.-C. (2017). Exploration on the New Practice Teaching Mode of Pharmaceutical Engineering Based on MOOC and VR. Pharmaceutical Education, 33, 65-68.

Tang, L.-J., Zhou, J.-X., Liu, W.-W., Wang, J., \& Ma, W.-X. (2014). Green Reform and Practice on the Drug Synthetic Reactions Experiment Course Teaching. Shandong Chemical Industry, 43, 129-131.

Wang, G.-C., Ouyang, Y.-Z., \& Peng, Z.-Y. (2016). Teaching Reform and Practice on Independent Experiment Course of Pharmaceutical Engineering Major. Shandong Chemical Industry, 45, 116-117.

Wu, M.-C., Zhao, Z.-J., Zhao, Y.-X., \& Luo, Z.-H. (2016). Discussion on Practice Teaching of Pharmaceutical Technology Course in Application-Oriented Universities. Guangdong Chemical Industry, 43, 290.

Xu, M.-L., Zhao, G.-R., \& Bai, P. (2004). Pharmaceutical Engineering Education in Foreign Universities. Higher Education in Chemical Engineering, 30, 12-13.

Yan, F.-Y., Liu, D.-Q., Wang, B., Zhang, H.-C., Chen, J.-J., \& Wang, D.-H. (2008). New Contents and Students Quality Cultivation in the Experiments of Pharmaceutical Engineering Specialty. Pharmaceutical Education, 24, 48-49.

Ye, Y. (2012). Exploration into the Multi-Level Innovative Model of Experiment Teaching in Pharmaceutical Engineering Specialty. China Medical Education Technology, 26, 102-104.

Ye, Y., \& Li, Y. (2014). Problems and Reform Measures in the Course of Productive Practice. The Guide of Science and Education, 11, 161-162.

Zhang, H., Yu, F.-Q., Zhang, X.-L., Wang, K., Wan, C.-J., Liu, Z.-W., \& Guo, J. (2015). Construction and Implement of an Academics and Pratice Teaching System of Pharmaceutical Engineering. Pharmaceutical Education, 31, 21-25.

Zhang, Y., Wu, X.-Y., \& Zhang, Y.-Y. (2013). Research on the Quality Standards of Pharmaceutical Engineering Course Experimental Teaching. Guangdong Chemical Industry, 40, 213. 